\title{
DEVERES HUMANOS FUNDAMENTAIS: UM OLHAR SOBRE A FACE OCULTA DA ERA DOS DIREITOS
}

\section{FUNDAMENTAL HUMAN DUTIES: A VIEW ON THE HIDDEN FACE OF THE RIGHTS’ ERA}

\author{
Osmar Veronese ${ }^{1}$ \\ José Francisco Dias da Costa Lyra² \\ Marco Antônio Preis ${ }^{3}$
}

Resumo: Direitos e deveres se constituem nas duas faces de uma moeda que sustenta o Estado Constitucional, tanto que não existem direitos sem deveres, tampouco deveres sem direitos, seja por não ser concebível um regime democrático assentado na exigência unilateral de deveres, seja por não haver garantia jurídica ou fática às declarações de direitos sem o cumprimento de deveres. A partir da constatação de que o tema dos deveres fundamentais é um dos mais esquecidos do constitucionalismo contemporâneo, investiga-se sua importância para integração do estatuto jusfundamental da pessoa humana, equilibrado entre direitos e deveres humanos, como resposta à crítica sobre o discurso quantitativo e à crise de eficácia dos direitos fundamentais. $\bigcirc$ artigo explora algumas aproximações conceituais, busca delinear as principais características dos deveres fundamentais como categoria jurídica autônoma, seu alcance, interpretação e limites para, alfim, sob o paradigma da solidariedade, verificar os contributos desse resgate para o desenvolvimento da cidadania e da democracia, bem como para conferir-se maior eficácia aos direitos fundamentais.

Palavras-chave: Deveres fundamentais. Direitos fundamentais. Dignidade humana. Estatuto da pessoa. Solidariedade.

\begin{abstract}
Rights and duties constitute the two sides of the same coin that supports the Constitutional State because it does not exist rights without duties or vice versa. It is not conceivable in a democratic regime based on the unilateral requirement of duties, the guarantee of rights without the fulfillment of duties because there is no legal or factual bases for such. It is verified that the subject concerning the fundamental duties is one of the most forgotten in the contemporaneous constitutionalism, consequently, it is investigated its importance for the integration of the fundamental law of human being, balancing human rights and duties, as an answer to the criticism about the quantitative discourse and about the fundamental rights efficacy crisis. The article aims to outline the main characteristics of the fundamental duties as an autonomous legal category, its range, interpretation and limits to, respecting the solidarity paradigm, verify the contribution of such rescue for the development of citizenship and democracy as well as to confer bigger efficacy to the fundamental rights.
\end{abstract}

Keywords: Fundamental duties. Fundamental rights. Human dignity. Statute of the human being. Solidarity.

Recebido em 3 de julho de 2018 Avaliado em 20 de abril de 2020 (AVALIADOR A) Avaliado em 20 de abril de 2020 (AVALIADOR B)

Aceito em 20 de abril de 2020

\footnotetext{
Doutor em Modernización de las Instituciones y Nuevas Perspectivas en Derechos Fundamentales pela Universidad de Valladolid, Espanha; Professor de Direito Constitucional na Graduação, Doutorado e Mestrado da Universidade Regional Integrada do Alto Uruguai e das Missões de Santo Ângelo; Procurador da República - Ministério Público Federal; Avenida Universidade das Missões, 464, Universitário, 98802-470, Santo Ângelo, Rio Grande do Sul; https://orcid.org/0000-0001-9927-7242; osmarveronese@gmail.com

2 Doutor em Direito pela Universidade do Vale do Rio dos Sinos; Professor no Programa de Pós-graduação Stricto Sensu em Direito - Doutorado e Mestrado e na Graduação da Universidade Regional Integrada do Alto Uruguai e das Missões de Santo Ângelo; https://orcid.org/0000-0003-1952-3365; jfdclyra@gmail.com

3 Mestre em Direito na Universidade Regional Integrada do Alto Uruguai e das Missões; Especialista em Direito Público pela Escola Superior da Magistratura do Estado de Santa Catarina; Juiz de Direito no Tribunal de Justiça do Estado do Rio Grande do Sul; https://orcid.org/0000-0002-2986-5388; m_preis@hotmail.com
} 


\section{Considerações iniciais}

As principais constituições contemporâneas e diplomas internacionais que versam sobre direitos humanos contam com uma seção específica sobre os direitos e deveres fundamentais. Dito de outro modo, no edifício jurídico democrático, construído nos últimos duzentos anos, as constituições e diplomas nacionais, ao lado das declarações (tratados e convenções) internacionais, representam o signo de uma era de contenção do poder político e de proteção das liberdades individuais. Tanto na via doméstica como na internacional, esses documentos são caracterizados por um catálogo de direitos fundamentais como a essência do constitucionalismo, publicizando princípios lastreadores do Estado de Direito, bem como, mais recentemente, do denominado neocontitucionalismo.

Nesses documentos, os direitos estão ampla e solenemente declarados, mas o principal desafio do nosso tempo é dar-lhes eficácia, concretizá-los na vida real das pessoas. Daí que, a despeito do inegável avanço que representou a normatização dos direitos humanos e fundamentais como base principiológica do Estado democrático de Direito, a anemia que sofrem em várias regiões do planeta, como na América Latina e no Brasil, fazem com que esses países sejam doutrinariamente classificados como de modernidade periférica ou tardia, os quais, por isso, podem conviver com o fenômeno da constitucionalização simbólica, retórica, de escassa concretude (direito opaco).

Sem desprestigiar o legado da teoria e da prática dos direitos fundamentais para o mundo, busca-se, no presente estudo, lançar luzes sobre a outra face, o lado obscuro dos direitos, a saber, os deveres humanos fundamentais, que se ressentem de um desenvolvimento teórico aprofundado, não tendo recebido, por compreensíveis razões históricas, atenção equivalente à dedicada aos direitos, pela ciência jurídica.

Como os deveres fundamentais são dirigidos tanto ao Estado quanto às pessoas, a pesquisa busca realizar um recorte epistemológico para os comandos dirigidos aos indivíduos, nas relações particulares (horizontais) e nas estabelecidas com o Estado, razão pela qual optou-se pela denominação deveres humanos, para distinguir dos deveres fundamentais de proteção do Estado (Schutzpflicht). Busca-se compreender as razões da hipertrofia dos direitos em relação aos deveres ao longo do processo histórico e político de desenvolvimento do constitucionalismo, bem como do resgate da dimensão da solidariedade e da responsabilidade como contribuições à edificação de uma noção mais completa de cidadania e, portanto, de democracia.

Como categoria operacional fala-se em deveres humanos fundamentais como o sistema de deveres jurídicos (posição passiva) humanos (voltados às pessoas físicas), consagrados em diplomas internacionais e nos textos constitucionais, marcados pela fundamentalidade formal (positivados com hierarquia superior e com procedimento qualificado de revisão) e material (integram o estatuto jusfundamental da pessoa humana), exigidos pelo Estado ou pela comunidade politicamente organizada (vertical) ou, ainda, pelas demais pessoas (horizontal), físicas e jurídicas, como obrigações jurídicas de dar, fazer (positivos) ou não fazer (negativos). 
Sob essa perspectiva, a teoria dos deveres fundamentais visa a equilibrar a relação entre direitos e deveres, entre liberdade e poder, entre indivíduo e sociedade e, com isso, dar efetividade aos direitos fundamentais, para além do discurso quantitativo de um acúmulo ilimitado de declarações em sucessivas camadas de gerações ou dimensões, desprovidas de garantias mínimas para seu exercício, nas quais o adimplemento dos deveres se insere. Procurar-se-á trabalhar, portanto, o tema dos deveres como categoria jusfundamental autônoma em relação aos direitos fundamentais, seu conteúdo estrutural e regime jurídico, para conferir um maior equilíbrio ao estatuto da pessoa, composto tanto por direitos invioláveis como por deveres inderrogáveis, ambos essenciais à vida em sociedade, para a edificação de uma pessoa ao mesmo tempo livre e responsável.

Para cumprir tal mister, seguindo a técnica de pesquisa bibliográfica, em abordagem qualitativa, o artigo, em um primeiro momento, apresenta a relação desigual existente entre os direitos fundamentais, que experimentam uma hipertrofia, procurando esclarecer os motivos que levaram a um desenvolvimento insuficiente sobre a temática dos deveres no constitucionalismo contemporâneo. Em um segundo momento, trabalhar-se-á com a necessidade de estruturar um estatuto jusfundamental da pessoa, composto tanto por direitos como por deveres para, desenvolvendo os deveres como categoria jurídica autônoma, chegar até a última seção do trabalho, que versa sobre os contributos para esse resgate teórico.

\section{A constitucionalização dos direitos $e$ a atrofia dos deveres: origens de uma relação desigual}

A construção histórica do Estado de Direito repousou sobre a reivindicação de direitos. Com todos os méritos das conquistas dos direitos humanos e fundamentais, inegável que a noção de Estado moderno se construiu sobre a reivindicação de direitos subjetivos individuais, desde o modelo liberal, passando pelo aparelhamento de bem-estar social até chegar aos sistemas democráticos contemporâneos. Mas, embora não tenha sido a ênfase das construções e discursos, os deveres sempre estiveram presentes nesse processo. Desde as origens da metáfora do "contrato social", inegável que além de direitos, liberdades e garantias dos indivíduos frente ao Estado, a coletividade exige também deveres para com o todo. Sem a pretensão de traçar uma narrativa linear da história do Estado moderno, mas seguindo as balizas consolidadas dos modelos liberal, social e democrático, tem-se que o fio condutor sempre foi a limitação de poder por parte dos cidadãos e da sociedade civil em relação ao Estado, o que se desenvolveu sob o signo da reivindicação de direitos.

Nesse ponto, Ferreira Filho (2013) ressalta que os antecedentes históricos das primeiras normas materialmente constitucionais são em defesa da Coroa francesa diante de monarcas fracos e frívolos, a necessidade prática de se organizar o exercício do poder do Estado para além do voluntarismo momentâneo do ocupante do trono. Era preciso estabelecer os deveres do próprio rei e uma estrutura mais institucional e menos pessoal de governo. Ou seja, apesar de a literatura constitucionalista expor 
a evolução do Estado de Direito sempre a partir das reivindicações de direitos, a história demonstra que os direitos e os deveres nascem e se desenvolvem juntos, conectados, porém a narrativa que se construiu a posteriori colocou os direitos à luz e os deveres nas sombras.

Nesse processo, portanto, olvidou-se da imposição de limites ao poder político pela sua dimensão oposta, a partir do instrumento que lhe é mais característico, qual seja, a imposição de deveres. Se o intuito é parametrizar a atuação legítima do poder dentro das balizas do direito, afigurase mais adequado estudar os conteúdos e alcances dos deveres impostos a todos, de dentro para fora, do que cercar o poder com direitos subjetivos, de fora para dentro.

Declarações de direitos partem do pressuposto de que a vida social tem como pedra fundamental os direitos individuais, enquanto que as declarações de deveres se fundam nos elementos basilares da sociedade. Desde os primeiros marcos históricos, Bandieri (2011) evidencia que a reforma constitucional francesa do ano III (1795) refletiu o giro político resultante das decepções acumuladas com os primeiros momentos revolucionários. $\mathrm{O}$ individualismo exacerbado e a pretensão de refundar a sociedade do grau zero do estado de natureza levaram a um retorno à valorização da ordem e dos laços interpessoais. $\bigcirc$ passo seguinte da experiência histórica francesa - mas que se destaca por ter influenciado todo o sistema jurídico ocidental, incluindo o Brasil - foi a consagração do Código Civil como principal código de normas e comportamentos nas relações, em um contexto de equilíbrio entre direitos e deveres, de cariz contratual, e baixa normatividade das previsões constitucionais.

Nabais (2007) recorda que o primeiro registro histórico da expressão direitos fundamentais data do ano de 1770, no contexto revolucionário francês, mas sua formulação jurídico-positiva é um fenômeno mais recente, ainda que suas raízes filosóficas remetam a tempos remotos. $\bigcirc$ Estado de Direito inicia marcado pela abertura de espaços de liberdade individual diante do poder estatal, por meio dos direitos subjetivos. Deixa-se a posição de súdito a adquire-se o status de sujeito de direitos autônomo. Com o esgotamento desse modelo e crise da igualdade material, a relação entre indivíduo e Estado se inverte, da reivindicação negativa de não intervenção estatal na vida humana, passa-se a uma visão do Estado como garantidor de todos direitos, individuais e coletivos.

Nesse novo patamar, o Estado deixa de ser uma ameaça e se converte em salvação. Essa mudança de perfil estatal se dá no período das revoluções industriais e sociais, uma etapa intermediária, em que a relação se inverte, mas não se transforma. A crise dessas promessas públicas de bem-estar social, sobretudo por razões econômicas, conduz a um exaurimento da relação entre homem e Estado, que não pode intervir em todos os aspectos da vida e não é capaz de fornecer tudo o que dele se exige. É o momento da proliferação de dimensões de direitos sem limites.

No contexto de crise de implementação dos direitos verticais e do aumento da complexidade das sociedades tecnológicas, surge a dimensão horizontal dos direitos, dando evidência às relações entre particulares, acentuando a incidência privada dos direitos fundamentais. Nesta, avulta a categoria dos "direitos de solidariedade", impondo a construção de um novo paradigma, de "sujeito de direitos" para "pessoa humana", que tem sua dignidade como o centro gravitacional do ordenamento 
jurídico e diretriz para a edificação de seu estatuto jurídico, composto tanto por direitos como por deveres fundamentais. Converge nesse sentido o fenômeno da internacionalização dos direitos humanos, do reconhecimento da subjetividade jurídica do indivíduo no direito internacional, de modo que todo o atentado contra os direitos da pessoa deixa de ser apenas uma questão doméstica e pode ser capaz de atingir a humanidade como um todo.

Para apresentar o estado da arte do sistema dos direitos fundamentais no constitucionalismo moderno e contemporâneo, Canotilho (2006) aponta a distinção entre direitos humanos e fundamentais, sendo os primeiros válidos para todos os povos e em todos os tempos (dimensão jusnaturalista universalista) e os segundos os direitos jurídica e institucionalmente garantidos e limitados no espaço e no tempo, objetivamente vigentes em uma ordem jurídica concreta. A partir de tal distinção, o autor trata do itinerário histórico clássico do reconhecimento dos direitos, identificados com o modelo de Estado. Com a ascensão do Estado de Direito, fruto das revoluções liberais burguesas para superação do absolutismo, firmam-se as liberdades e garantias aos direitos individuais, civis e políticos, no paradigma absenteísta de salvaguardar a pessoa contra os arbítrios do Estado (status negativus), tendo como marco jurídico a Declaração de Direitos francesa de 1789 e o princípio da legalidade.

Sob o signo da igualdade material e identificados com o modelo de Estado social, fruto das revoluções socialistas, de trabalhadores e com o fim da Primeira Guerra Mundial, ascendem ao plano constitucional os direitos sociais, econômicos e culturais, de paradigma intervencionista e prestacional do Estado, por meio de políticas públicas voltadas ao bem-estar social, como forma de amenizar as crises econômicas e o contexto de desigualdade social, tendo como marcos jurídicos as Constituições do México, de 1917, e da Alemanha, de 1919 e o desenvolvimento dos mecanismos de controle de constitucionalidade das leis.

Não se trata de um conjunto de direitos que se contrapõe ao anterior, mas outros direitos fundamentais, sujeitos ao mesmo regime geral, porém não se beneficiando do regime especial das liberdades, direitos e garantias individuais (sobretudo quanto ao ponto da aplicabilidade imediata). Não há uma sucessão de camadas de gerações de direitos, a sugerir uma certa prevalência ou hierarquia entre tais conjuntos de direitos, mas, uma vez consagrados nos textos jurídicos, se sujeitam ao esforço uniformizador e sistematizador da hermenêutica constitucional, que ganha complexidade e enriquece o estatuto e o patrimônio jusfundamental da pessoa.

Seguindo essa linha de raciocínio, chega-se ao momento histórico-político do segundo pósguerra e da necessidade de se compatibilizar todo este arcabouço de direitos consagrados a uma ordem política democrática e que tenha como eixo interpretativo a dignidade da pessoa humana. Ascendem ao plano constitucional, portanto, os direitos ligados à solidariedade ou à fraternidade, de caráter difuso e transgeracional, tendo como marcos jurídicos a Declaração de Direitos das Nações Unidas, de 1948, o controle de convencionalidade a ordens jurídicas supranacionais e a centralidade da jurisdição constitucional. 
Apesar da simplificação ilustrativa na divisão destes três grandes momentos, Pérez Luño (2013) pondera que nenhuma ordem jurídica vivenciou historicamente uma sucessão clara destes paradigmas, mas momentos políticos de preponderâncias, avanços e retrocessos, bem como a coexistência conflituosa entre as características próprias de cada um dos modelos apresentados. Muito embora se viva um tempo de incertezas, a literatura constitucionalista contemporânea converge na constatação de que o constitucionalismo mudou, de modo a falar-se hoje em vários neoconstitucionalismos, rótulo sob o qual se incluem análises de diversos fenômenos que impactam o paradigma do Estado ao longo do tempo e o desenvolvimento da respectiva Teoria do Direito explicativa dessas mudanças.

Nessa linha, Barroso (2015) divide esse processo três marcos: (i) histórico, (ii) filosófico, e (iii) teórico. O marco histórico trata do constitucionalismo valorativo europeu (continental) do segundo pós-guerra (Alemanha e Itália na década de 1940, Portugal e Espanha na década de 1970) e, no Brasil, na década de 1980, convergindo com o processo de redemocratização que culminou com a Constituição de 1988. O marco filosófico é o pós-positivismo, a terza via entre jusnaturalismo e o juspositivismo, como expressão da superação da oposição entre modelos puros por um conjunto inclusivo e abrangente de características de ambos que se agrupou sob o rótulo genérico de póspositivismo. A superação histórica do jusnaturalismo (anti-científico) e o fracasso político do juspositivismo (legalidade de regimes nazi-fascistas) abriu espaço para reflexões acerca da função social e da interpretação do direito, para além da legalidade estrita, mas sem desprezar o direito positivo, com uma releitura moral do direito, mas sem recorrer a categorias metafísicas.

marco teórico aponta três conjuntos de mudanças principais: (i) força normativa e aplicabilidade direta e imediata das disposições constitucionais; (ii) a expansão da Jurisdição constitucional. A ideia do controle de constitucionalidade fez surgir a doutrina da Supremacia da Constituição, rompendo com as tradicionais doutrinas inglesa e francesa de supremacia do Parlamento e da lei como vontade geral. A fórmula nova envolvia a constitucionalização dos direitos fundamentais, que ficavam imunizados do processo político majoritário, deslocando a esfera de proteção do Legislativo para o Judiciário. A terceira mudança foi o desenvolvimento de uma nova hermenêutica constitucional (cláusulas gerais, princípios, ponderação, argumentação). $O$ fenômeno da constitucionalização do direito vincula todos os Poderes e também os particulares, diretamente, ultrapassa as fronteiras dos direitos subjetivos e institui uma ordem objetiva de valores, pois o sistema jurídico deve proteger determinados direitos e valores, não apenas pelo eventual proveito a uma ou a algumas pessoas, mas pelo interesse geral da sociedade na sua satisfação. A patologia social hodierna é a conjugação incompatível de uma ideologia individualista, sob o viés demandista e reivindicatório de prestações sociais pelo Estado.

A constitucionalização é um processo de transformação do ordenamento jurídico, que se torna impregnado pelas normas constitucionais, caracteriza-se por uma constituição invasiva, capaz de condicionar a legislação ordinária, a jurisprudência, o estilo doutrinário, as ações dos atores 
políticos e demais relações sociais. Essa é uma noção que comporta graduações, de modo que um ordenamento pode estar mais ou menos constitucionalizado, conforme sete condições apresentadas por Guastini (2003):

a) rigidez constitucional, com um texto escrito e um procedimento especial de revisão, ocupando o degrau mais elevado do ordenamento jurídico;

b) garantia jurisdicional, com controle de constitucionalidade por um órgão próprio;

c) difusão na cultura jurídica de que toda a norma constitucional é cogente, vinculante e suscetível de produzir efeitos jurídicos imediatos;

d) sobreinterpretação constitucional;

e) aplicação direta das normas constitucionais;

f) interpretação da legislação ordinária conforme a constituição;

g) influência sobre as relações políticas.

Um traço característico do neoconstitucionalismo é seu foco no Poder Judiciário, tendo o Juiz como protagonista e analisando o direito a partir de uma perspectiva interna, do intérprete e aplicador, relegando a um segundo plano as perspectivas de observadores externos. Essa posição do Juiz como o guardão das promessas civilizatórias é o ponto que expõe o neoconstitucionalismo às maiores críticas. $\bigcirc$ constitucionalismo contemporâneo, porém, não é uma ruptura radical com o constitucionalismo moderno desde o Estado liberal, mas muito mais um avanço e um aprimoramento no sentido de garantir a liberdade dos cidadãos e limitar o poder do Estado. Representa mais uma alteração na prática constitucional do que uma oposição aos seus fundamentos teóricos.

Não incumbe ao constitucionalismo, velho ou novo, resolver todos os conflitos políticos, como destaca Violante (2014), mas a reflexão sobre a democracia deve reconhecer os limites estruturais do Direito e da jurisprudência, a função democrática do conflito e os efeitos da esterilização da democracia e da cidadania decorrentes da ilimitada delegação ao Poder Judiciário para reconhecimento de (novos?) direitos.

Convém repisar que os principais diplomas internacionais e as constituições democráticas da atualidade consagraram uma seção sobre os direitos e deveres fundamentais. No sistema global, a Declaração Universal dos Direitos do Homem, âmago do constitucionalismo contemporâneo, prevê o dever de todos os seres humanos, dotados de razão e consciência, para com a comunidade na qual o livre e pleno desenvolvimento de sua personalidade é possível (ORGANIZAÇÃO DAS NAÇÕES UNIDAS, 1948).

No sistema regional americano, desde o preâmbulo, a Declaração Americana dos Direitos e Deveres do Homem (ORGANIZAÇÃO DOS ESTADOS AMERICANOS, 1948) dispõe que "O cumprimento do dever de cada um é exigência do direito de todos. Direitos e deveres integramse correlativamente a toda a atividade social e política do homem. Se os direitos exaltam a liberdade 
individual, os deveres exprimem a dignidade dessa liberdade" e, na sequência, prevê um capítulo próprio, com dez artigos elencando deveres fundamentais, voltados sobretudo à educação, ao voto, ao trabalho, ao pagamento de tributos, à prestação de serviços civis e militares, além do dever geral de convivência "de maneira que todos e cada um possam formar e desenvolver integralmente a sua personalidade."

Em âmbito doméstico, a Constituição da República Federativa do Brasil de 1988 inaugura a seção jusfundamental com o capítulo sobre os direitos e deveres individuais e coletivos e, em seu corpo, institui o alistamento e voto obrigatórios (art. 14), serviço militar compulsório (art. 143), a segurança pública como responsabilidade de todos (art. 144), o dever geral de pagar impostos (art. 145), a educação como dever familiar (art. 205), compulsória educação básica (art. 208, I), o meio ambiente ecologicamente equilibrado como dever de defesa e preservação por parte de todos (art. 225), dever geral de proteção das crianças, adolescentes e jovens (art. 227), deveres recíprocos de amparo entre pais e filhos (art. 229), dever geral de proteção dos idosos (art. 230) entre outros (BRASIL, 1988) - mas apesar dessa positivação formal, pouco se fala, se escreve ou se interpreta quando o assunto é dever, sua incidência, seu conteúdo, seus limites.

Por isso que Nabais (2015) apresenta o tema dos deveres fundamentais como um dos mais esquecidos da literatura constitucional contemporânea, assim como o das demais situações jurídicas passivas, ou seja, sujeições, ônus, deveres, obrigações dos particulares no direito público, e aponta como a principal causa desse escasso desenvolvimento teórico a tensão no constitucionalismo atual entre o poder, que tem a dominação na essência, e o direito, cujo papel precípuo é justamente o de limitar o poder, de modo a assegurar aos cidadãos maior âmbito de liberdade e autonomia.

Para ilustrar e demonstrar quantitativamente a dimensão desse esquecimento dos deveres, alguns autores se dedicaram a elaborar um levantamento em buscadores de pesquisas de publicações e de bancos de dados públicos, acerca da ocorrência das expressões direitos fundamentais e deveres fundamentais. Nesse sentido, Lanchester (2010) identificou que na França, enquanto 151 títulos eram dedicados aos deveres 6.175 se dedicavam a direitos; na Alemanha foram 89 títulos para os deveres e 1.873 para os direitos; no âmbito anglo-americano, foram contabilizados 89 títulos aos deveres e mais de 10.000 dedicados aos direitos. No Brasil, Siqueira (2012) apurou 1,81 mil ocorrências para deveres fundamentais e 38,8 mil para direitos fundamentais. Ainda que limitadas à mera referência, são números significativos a dimensionar a distância entre direitos e deveres, e, por isso mesmo, desses dados, é possível se inferir, por todas as leituras realizadas e referidas ao final da pesquisa, que a grande maioria das referências aos deveres fundamentais são breves, superficiais, limitadas e demasiadamente atreladas aos direitos. Quase inexistem obras que se dediquem a sistematizar e a aprofundar a temática como um objeto autônomo de pesquisa.

O principal fator histórico e geopolítico desse esquecimento foi o fato de que a maior parte das constituições atuais ter sido produto de movimentos sociais e políticos de superação de regimes autoritários, os quais atribuíam uma predominância absoluta ao status passivo (status subjectionis) do cidadão frente ao Estado, tendo nas declarações de direitos dos textos constitucionais uma forma de 
exorcizar tais regimes e de evitar aberturas interpretativas para novas formas de regimes totalitários, como são exemplos evidentes as Constituições italiana, de 1947, alemã, de 1949, portuguesa, de 1976, e espanhola, de 1978, que mais diretamente influenciaram a produção do texto normativo da Constituição brasileira de 1988.

Contextos históricos como o nazismo e o comunismo explicam a desconfiança, a indiferença ou mesmo o rechaço aos deveres, mas, consoante Canotilho (2006) observa, os tempos são outros, de maturidade democrática que permite uma reproblematização dessa importante categoria jurídica e política, pois os deveres tratam da articulação entre o indivíduo e a comunidade. Quando se fala, hoje, em direitos humanos e fundamentais remete-se a algo inato, atemporal, prévio à organização social e política, inerente ao ser humano pelo simples pertencimento à espécie, positivados no plano internacional a ponto de se converterem em uma superconstituição cosmopolítica da pós-modernidade. Noutro vértice, quando se fala em deveres humanos e fundamentais remete-se a determinados comportamentos considerados valiosos para uma comunidade, portanto pressupõem uma organização política e jurídica estabelecida, ou seja, mais condicionados a conjunturas culturais e históricas.

Peces-Barba Martínez (1987) entende possível encontrar uma teoria dos deveres fundamentais na origem do sistema político moderno, pois a justificação contratualista clássica, em que pese as diferenças entre os autores (Pufedorf, Hobbes, Locke, Rousseau, Kant), foi construída sobre uma ficção racional, a qual se acrescentam posições mais recentes e plurais (Rawls, Nozick, Buchanan, Habermas), sobre a existência de um modelo de deveres recíprocos, dos cidadãos e dos governantes, em uma situação comunicativa ideal. $O$ poder do Estado é aceito pelas pessoas para a segurança de todos, para o desenvolvimento da comunidade política e para a proteção dos direitos fundamentais. Com essa finalidade, os homens se unem em sociedade se situam sob a proteção do Estado. O dever do poder político é governar de modo justo e correto para salvaguardar em maior medida os direitos das pessoas e, em contrapartida, o dever das pessoas, em uma sociedade assim constituída, é obedecer ao Direito.

Variando dos deveres negativos de abstenção estatal aos deveres positivos de prestação estatal, essa estrutura se manteve até o segundo pós-guerra, quando o tema da obediência ao Direito adquiriu novos contornos em uma sociedade democrática, com o desenvolvimento de teorias que justificam a desobediência civil e a objeção de consciência frente a um Direito injusto. $\bigcirc$ efeito dessa atrofia teórica dos deveres fundamentais em relação aos direitos, segundo Castanheira Neves (1996), é fazer perder de vista a ideia de responsabilidade comunitária, o que faz dos indivíduos seres simultaneamente livres e responsáveis, ou seja, pessoas autônomas.

Em que pese a discrição do tema, os deveres fundamentais constituem uma exigência estrutural inerente a qualquer constituição, pois mais do que visarem a comportamentos dos particulares, constituem a legitimação para a intervenção dos poderes públicos em determinadas relações sociais e em determinados âmbitos da autonomia pessoal dos cidadãos. Em geral, as pessoas se sentem portadoras naturais de direitos que todos devem reconhecer, credoras do Estado, 
consumidoras de prestações, mas dificilmente se pensa que, para isso, também pesam deveres sobre as pessoas. Essa hipertrofia dos direitos paralela ao esquecimento dos deveres causa um efeito nocivo nas bases estruturais da sociedade, pois a ideia de solidariedade se esvazia e frustram-se as expectativas de concretização dos direitos.

Reflexões contemporâneas de toda a ordem evidenciam essa constatação, de que de um lado reivindicam-se presumidos direitos, não raro de caráter supérfluo, com a pretensão de que as estruturas públicas os reconheçam e promovam, e, por outro lado, há direitos elementares e fundamentais que se ignoram ou violam em grande parte da humanidade. Essa relação de direitos individuais, desvinculados de um conjunto de deveres que lhes dê um sentido profundo, dá lugar a uma espiral de exigência ilimitada e carente de critérios. Os deveres delimitam os direitos porque remetem a um marco antropológico e ético que reforçam os direitos. Por isso, compartilhar os deveres recíprocos mobiliza muito mais do que a mera reivindicação de direitos (BENTO XVI, 2009).

Nesse sentido, Sarlet (2018) sustenta que, a despeito da topografia, a categoria constitucional dos deveres fundamentais não se limita à esfera individual, alcançando deveres de natureza política, social, econômica, cultural e ambiental. Necessária uma leitura integral e sistêmica da ordem constitucional, para além da primazia da postura não intervencionista do Estado sobre o indivíduo, a denotar uma noção de cidadão pouco ou nada comprometido com a sua comunidade e com seus semelhantes. Assim, paradoxalmente, a valorização do discurso dos deveres veicula uma crítica ao discurso quantitativo de um catálogo crescente e ilimitado de direitos, sem maiores preocupações institucionais com sua incidência concreta na sociedade, mas também representa limites à atuação estatal, na medida em que disciplina com maior detalhamento o conteúdo e a dimensão dos deveres, delimitando seus contornos legítimos.

$\mathrm{Na}$ atual quadra, com as sociedades confrontadas com a globalização, verifica-se um acentuado individualismo que se expressa no constitucionalismo como a preponderância de uma identificação dos direitos humanos e fundamentais com sua dimensão de direitos subjetivos individuais, uma inflação legislativa consagradora de enunciações de direitos, sem uma séria responsabilidade e compromisso com sua eficácia e com os custos sociais que representam para a coletividade (HOLMES; SUNSTEIN, 1999).

O resultado da profusão de direitos sem a definição e explicitação clara dos correlativos deveres, na perspectiva de Silva (2015), tem a tendência, em médio e longo prazo, de levar à erosão dos próprios direitos fundamentais, já que o cidadão, por não compreender que a vida em sociedade pressupõe também deveres, passa a enxergar que tem apenas direitos de cumprimento obrigatório pelo Estado.

\section{Os deveres como categoria autônoma e o estatuto da pessoa}

Assim como outros tantos conceitos jurídicos, dentre eles os próprios direitos fundamentais, os deveres surgiram historicamente nos domínios religioso e ético e, aos poucos, migraram para 
o campo do direito com contribuições do humanismo jurídico, do jusnaturalismo racionalista e do pensamento estoico, aproximando os valores de justiça social ao individualismo, de modo a transformar o homem em titular não só dos direitos inerentes à sua dignidade, mas também dos deveres que a existência e o funcionamento da comunidade organizada implicam. Com base nessas ideias surgem os deveres gerais de solidariedade e de não causar dano a outrem, de restituir o alheio, de manter a palavra dada, de reparar os danos causados, e que a violação a tais regras merece punição, erigindo este elemento em traço identificador dos deveres (PECES-BARBA MARTÍNEZ, 1987).

$\mathrm{Na}$ atual quadra, o que deve ser (re)afirmado são os deveres fundamentais autônomos, uma vez que os deveres passivos ou correlativos dos direitos (deveres de abstenção do Estado e dos particulares, bem como deveres de proteção e promoção estatal), enquanto faces passivas dos direitos, já estão consagrados pela teoria dos direitos fundamentais. Nesse ponto, Canotilho e Leite (2007) compartilham do entendimento de que os deveres não se resumem àqueles em relação aos quais haja um direito previamente estatuído pelo legislador, deduzíveis ou derivados de direitos outorgados, mas, ao contrário, exprimem deveres fundamentais diretos, a partir dos quais se reconhecem poderes e beneficiários para fazê-los valer.

Sem a pretensão de apresentar conceitos definitivos, Nabais (2015) condensa as principais características para a construção de um conceito aproximativo dos deveres fundamentais como a mobilização do homem e do cidadão no campo jurídico para a realização dos objetivos do bem comum. São deveres jurídicos de especial significado para a comunidade, exigíveis pela ordem jurídica vigente, para comportamentos ativos ou passivos, posições jurídicas passivas, autônomas, subjetivas, individuais e universais, que independem das vontades de seus titulares, aplicáveis tanto em relação direta com o Estado (eficácia vertical) como na relação entre as pessoas (eficácia horizontal). Trata-se de encargos ou sacrifícios em prol da comunidade, que valem indistintamente a todos os indivíduos (generalidade, universalidade), o que não afasta algumas incidências relativas, como no caso dos deveres eleitorais (voto, recenseamento e serviços de escrutínio) ou militares (alistamento compulsório) apenas para os cidadãos nacionais que tenham atingido determinada idade, ou nos casos específicos, de mantença e educação dos pais em relação aos filhos. Não são previsões incompatíveis com o conceito, mas mera delimitação dos deveres a partir das relações jurídicas e das condições para seu exercício regular (capacidade), limitadas pela ordem jurídica.

Apesar das divergências doutrinárias, Siqueira (2016) adota a perspectiva de que os deveres assumem sentido amplo, circunscrevendo deveres em sentido estrito, que levam em consideração interesses gerais e objetivos, enquanto que as obrigações dizem respeito a interesses individuais e subjetivos. Não são, todavia, categorias separadas, pois o cumprimento dos deveres estabelece obrigações concretas. Normas jurídicas que estabelecem obrigações devem ser normas que ordenam ou proíbem comportamentos, pois expressam mandados, positivos ou negativos, ao contrário de normas permissivas e potestativas, que estabelecem faculdades ou autorizam comportamentos. 
Delimitados os elementos tipológicos dos deveres fundamentais é possível excluir algumas figuras próximas, mas que não se confundem, como os deveres constitucionais organizatórios, orgânicos ou funcionais, que são competências obrigatórias dos órgãos do Estado e que integram sua organização política (SCHMITT, 1986), sem necessária correspondência com o conteúdo material jusfundamental nem com o estatuto constitucional do indivíduo. Outra figura diversa são os ônus, pois enquanto os deveres consistem em uma necessidade jurídica de adoção de um determinado comportamento, os ônus concretizam-se pela necessidade prática em que se encontra o detentor de um poder reconhecido pela ordem jurídica para praticar certo ato a fim de conseguir a produção de efeitos jurídicos favoráveis, como no caso do ônus do jurisdicionado de comprovar a hipossuficiência econômica para gozar da gratuidade judiciária, conforme disposto no art. $5^{\circ}$, LXXIV, da Constituição brasileira (BRASIL, 1988).

Para que se trate de deveres fundamentais é necessário que se esteja diante de normas de conteúdo jusfundamental relativas a posições subjetivas que integrem o estatuto jurídico da pessoa e não perante consequências individuais de normas de organização política, econômica ou administrativa do Estado. Assim, estados de sujeição decorrentes do poder de legislar, do poder punitivo, do poder expropriatório, do poder de polícia, do poder regulamentar, do poder disciplinar, do poder judicial, por exemplo, não configuram deveres fundamentais, por serem reflexos subjetivos do estatuto organizatório do Estado.

Compreendido o objeto de estudo, o que são os deveres fundamentais e sua distinção de figuras jurídicas próximas, convém estudar seu conteúdo material, o que dá sentido aos contributos à cidadania e aos direitos fundamentais.

Em regra, aplica-se aos deveres fundamentais o mesmo regime dos direitos fundamentais, que abarca aspectos da universalidade, igualdade, defesa jurisdicional, direito de resistência a ordens para além do constitucionalmente permitido, responsabilização dos agentes públicos pela imposição de deveres inconstitucionais ou desproporcionais etc. Todos os deveres fundamentais limitam, pela sua natureza, a esfera de liberdade dos indivíduos, algo necessário para uma harmônica composição de interesses opostos, para impedir tanto a prevalência do Estado como um reconhecimento sem limites dos direitos dos indivíduos. São, portanto, autorizações para o legislador ordinário restringir, limitar, condicionar direitos, liberdades e garantias fundamentais (CARBONE, 1968).

Segundo o conteúdo, os deveres podem ser positivos ou negativos, conforme prescrevam comportamentos ativos - que podem se desdobrar em deveres de prestação personalíssima, infungíveis, que veiculam um facere, como o serviço militar e o voto, ou uma prestação de coisa (dare), como o pagamento de impostos - e comportamentos omissivos, deveres de abstenção (non facere), como a isenção político-partidária à Magistratura. Há também figuras mistas, como os deveres de preservação e promoção do meio ambiente, ao mesmo tempo, abstenção a ofensas a tais bens jurídicos e realização de condutas ativas para sua preservação (facere e non facere) ou os deveres de manutenção e educação dos filhos, que veiculam aspectos materiais de facere e dare. 
A maioria dos autores, como Carbone (1968) e Chulvi (2001) e Nabais (2007, 2015) entendem que os deveres fundamentais não têm aplicabilidade direta e imediata, mas necessitam de uma prévia mediação legislativa. São mandados constitucionais ao legislador ordinário para que concretize e sancione o descumprimento de seu conteúdo, para, só então, se tornar vinculante aos cidadãos e ao restante dos poderes públicos. São categorias jurídicas abstratas que implicam situações de sujeição com a necessidade de concreção legislativa a deveres genericamente formulados. Não criam uma expectativa de comportamentos privados, mas uma ordem de atuação aos poderes públicos, sendo necessária a intervenção do legislador para que, em uma norma de hierarquia legal, se imponha uma conduta que obrigue os cidadãos e sua correspondente sanção por descumprimento.

No entanto, precisa a ponderação de Sarlet (2018) no sentido de que os deveres fundamentais podem, a depender do caráter da norma jusfundamental, ter eficácia e aplicabilidade imediatas, com o reconhecimento de alguns efeitos, como revogação da legislação anterior manifestamente contrária e inconstitucionalidade de atos estatais posteriores, mas com necessária mediação legislativa quando as sanções por descumprimento forem de natureza penal, administrativa e econômica.

Analisados os caracteres centrais da categoria dos deveres fundamentais e sua inserção no ordenamento jurídico, o itinerário dessa apresentação desemboca na construção de um sistema complexo de interpretação dos direitos e deveres humanos, integrantes de um mesmo estatuto da pessoa.

A perspectiva de indivíduo como sujeito de direitos acompanhou e acompanha toda a construção da noção de ser humano desde os princípios da modernidade até a atualidade. Toda a construção dos direitos humanos e fundamentais se lastreou nessa perspectiva. $O$ indivíduo como portador de direitos subjetivos exigíveis em face de todos contra todos. É justamente esse viés unilateral dos direitos que se busca superar por meio da emergência de um novo paradigma, o do ser humano como "pessoa", perspectiva que se fundamenta na dignidade da pessoa humana. A pessoa como um ser equilibrado, dotado de um feixe de direitos e deveres para com a coletividade onde vive, tendo como pressuposto a liberdade com responsabilidade social, pois não se pode ter direitos nem deveres jurídicos sem liberdade de agir.

É nessa interseção entre os papéis de súdito e sujeito que se constrói a noção de pessoa, pois não se pode desfazer todas as conquistas dos direitos humanos e fundamentais, mas não se pode viver em uma sociedade em que cada indivíduo se limita a exigir direitos para si. Há uma parcela de submissão legítima devida por todos os que vivem em uma sociedade organizada. É sobre essa parcela de submissão legítima que se voltam às atenções do presente estudo. São os deveres humanos fundamentais, a que se propõe o resgate com o objetivo de trazer uma maior compreensão e, por conseguinte, a possibilidade de fixar com mais clareza os contornos e limites da legitimidade de sua aplicação.

A partir da constatação de que os deveres se tratam de normas constitucionais, de cunho jusfundamental, que se aplicam a todos indistintamente, independentemente das vontades de 
seus destinatários, é preciso delimitar os seus contornos e formas de aplicação com mais precisão e segurança. É essencial desvelar o manto da invisibilidade que recai sobre as normas com esse caráter para, assim, reforçar as garantias individuais a partir de outro lugar, outro locus de observação. Traçando-se um paralelo com o Direito Penal, o estudo das categorias jurídicas não se destinam necessariamente a legitimar o poder veiculado na norma, mas dar-lhe balizas de uma aplicação legítima. Com os deveres se passa o mesmo. Na esteira do Direito Constitucional, que não se volta necessariamente à legitimação do poder (político), mas a dar-lhe contornos seguros de legitimidade para as ingerências sobre a esfera jusfundamental das pessoas.

Interpretar os deveres também como norma jusfundamental exige a compreensão do momento inicial de consagração jurídica dos direitos, liberdades e garantias nos planos constitucional e internacional, mas é preciso avançar para fugir da perspectiva individualista e, com isso, caminhar no sentido de conferir-se maior eficácia aos direitos de todos, levando a sério seus custos de implementação e exercício para a comunidade política organizada, comprometida com sua salvaguarda. Também reforça e completa a noção de cidadania dos indivíduos, pessoas que convivem em sociedade e são os beneficiários últimos dessas conquistas, resgatando noções de liberdade com responsabilidade e solidariedade jurídica, um feixe de expectativas normativas de modo a edificar um ser humano dotado e consciente de seus direitos e deveres para com os demais.

Os deveres fundamentais integram, para Nabais (2015), a matéria dos direitos fundamentais na (sub)constituição do indivíduo, que não se esgota na figura dos direitos, mas abarca outras categorias que, embora gravitando em seu redor, com eles não se confundem, como são as garantias institucionais, os deveres fundamentais e outros vetores da dimensão objetiva dos direitos fundamentais de efeitos extrasubjetivos. Complementa Chulvi (2001) que, em que pese os deveres sejam categorias constitucionais autônomas, gravitam em torno dos direitos fundamentais, pois estão vinculados, uma vez que ambas as categorias identificam o estatuto constitucional da pessoa em um Estado democrático de direito. Ao tratar dos deveres fundamentais, reunir as duas faces do estatuto constitucional da pessoa, a face dos direitos e a face dos deveres fundamentais, ancorada na ideia de que a pessoa é um ser simultaneamente livre e responsável, titular de direitos e encarregado de deveres, contribuindo para combater a visão unilateral e desfocada da pessoa que o individualismo impôs.

Essa ideia traduz uma compreensão equilibrada entre direitos e deveres em um Estado democrático de direito. Um ponto de equilíbrio entre a predominância dos deveres, própria dos Estados totalitário, e o exclusivismo dos direitos nas sociedades hiperindividualistas, o que leva a uma desagregação social, esvaziamento da noção de cidadania e da dimensão da eficácia dos direitos fundamentais. Não há direitos sem deveres porque não há garantia jurídica ou fática às declarações de direitos sem o cumprimento dos deveres do homem e do cidadão indispensáveis à existência e funcionamento de uma comunidade politicamente organizada, sem a qual os direitos não podem ser assegurados nem exercidos. Em contraponto, não há deveres sem direitos, porque não é concebível 
um regime democrático assentado na exigência unilateral de deveres, sem o amparo nas mais elementares exigências de justiça e de respeito aos direitos fundamentais e à dignidade humana. São categorias conectadas funcionalmente, em que se reconhece a primazia dos direitos e das liberdades fundamentais, sem perder de vista as responsabilidades e exigências e do bem comum.

O estatuto jurídico da pessoa é composto por um conjunto de normas que veiculam direitos e deveres, no plano constitucional e internacional, como integrante de uma comunidade política organizada, com fundamento tanto na dignidade humana transcendental do indivíduo, como na responsabilidade social e comunitária concreta, de modo a alcançar-se um desejável equilíbrio entre os valores jurídicos fundamentais da liberdade e autonomia do indivíduo, conjugada com a igualdade substancial e democrática, e o plano da solidariedade ou fraternidade em sentido global.

Enfim, direitos e deveres humanos fundamentais são destinados a servir à proteção da dignidade humana, tanto como garantia contra violações do poder (político) do Estado, como garantida (pelo Estado) contra violações dos poderes sociais, notadamente econômicos e culturais, de modo que toda a interpretação acerca dos deveres humanos fundamentais deve seguir essa relação triangular entre deveres, direitos e dignidade humana. Deve-se aplicar a norma jusfundamental de modo a dar-se máxima concreção ao dever fundamental, sem afetação ao núcleo essencial de um direito fundamental anexo ou correlato, e observada a finalidade de melhor atender às exigências da dignidade humana.

\section{Solidariedade, responsabilidade e cidadania}

Examinados os aspectos objetivos no caminho ao desenvolvimento de uma teoria dos deveres fundamentais é preciso ter presente a importância da matéria. De nada adiantaria o mero resgate de um assunto esquecido com fim em si mesmo, como um tema do passado, cujo único mérito é ser contramajoritário. Não se está diante de um mero interesse histórico, mas rumo a uma construção mais completa do estatuto jusfundamental da pessoa humana, o que impacta no plano jurídico, com a dimensão da solidariedade na eficácia dos direitos fundamentais, bem como no subjetivo, com o aprimoramento da cidadania.

No desenvolvimento do constitucionalismo, após os períodos de consagração das liberdades e do desenvolvimento da igualdade, em suas dimensões complexas, coloca-se atualmente a questão de compatibilizar, harmonizar, equilibrar essas duas forças, esses dois valores fundamentais para todas as sociedades humanas. Vive-se, portanto, o momento da consagração de uma nova dimensão, a da solidariedade, uma ideia que não traz consigo um valor novo por si, mas carrega a ideia desse terceiro elemento estabilizador, que completa e equilibra a dicotomia e as antinomias entre os ideais de liberdade e de igualdade, de direitos e deveres.

Todas as demandas contemporâneas por reconhecimento da diversidade nada mais são que expressões, manifestações mais complexas, por refletirem as sociedades atuais, do mesmo 
ideal de liberdade. A liberdade comporta regramento e limitação, sob pena de converter-se em um individualismo que (re)produz injustiças sociais, ao passo que a igualdade também não pode conduzir aos excessos de aniquilar a autonomia do indivíduo. São contribuições histórico-filosóficas que se complementam, não se excluem, mas cujo exercício exige a assunção de um ponto de vista diverso, capaz de compatibilizá-los em uma relação triangular, com o resgate de relações horizontais entre as pessoas e entre pessoas e instituições, para além das relações com o Estado, de abstenção liberal ou de monopólio socialista. Uma dimensão que exige a responsabilidade e o compromisso conjunto de comunidade (cum + munus), para além dos direitos subjetivos, na interseção entre a liberdade com responsabilidade e a igualdade com respeito às diferenças.

O que une todas as concepções de comunidade, desde contratualistas liberais a comunitaristas, é uma propriedade que une os sujeitos, um atributo, um predicado que os qualifica como pertencentes ao mesmo conjunto ou uma substância produzida por essa união. No entanto, Esposito (2012) propõe uma perspectiva distinta, cujo ponto de partida é a etimologia do termo latino communitas, derivado de communis, como aquilo que não é próprio, que concerne a mais de um, a muitos ou a todos e que, portanto, é público, geral, coletivo, em oposição ao privado, particular.

A pesquisa adota essa perspectiva como teoria filosófica de base social, que traz em seu interior a expressão munus e remete à ideia de dever, obrigação, função, encargo. Uma vez que alguém aceita o munus, está obrigado (onus) a retribuí-lo com bens ou serviços (officium) e, assim, se sobrepõem munus e donum, como restituição ou recompensa adequada. É um dom que se dá porque se deve dar e não se pode não dar. A obrigação que se contraiu com o Outro e requer uma adequada desobrigação, pois é algo que não se pode conservar para si, pois não se é dono. Essa gratuidade exige nova doação. O que prevalece é a reciprocidade, a mutualidade (ESPOSITO, 2012).

$\mathrm{Na}$ vida das pessoas, a solidariedade se manifesta na ideia de cidadania, tão antiga como a cultura jurídica ocidental e cujo significado se manifesta desde o Direito Romano. Agora, porém, Nabais (2007) acrescenta que a noção de solidariedade ganha significado no direito público, movida pela preocupação de encontrar uma resposta adequada à questão social para além do socialismo de Estado, como um caminho do meio entre o liberalismo e o socialismo, que ressurge no panorama do constitucionalismo contemporâneo com as recentes dimensões de direitos fundamentais, ligados sobretudo à ecologia e à democracia.

O conceito clássico de Marshall (1992) para cidadania é a qualidade dos indivíduos que, enquanto membros de uma determinada comunidade política, são titulares e destinatários de um conjunto de direitos e deveres universais e, por conseguinte, detentores de um específico nível de liberdade e de igualdade, com possibilidade de contribuir para a vida pública dessa comunidade através da participação. A partir desse standard a realidade mostra fenômenos extremos como a sobrecidadania e a subcidadania, de modo a se tratar de níveis ou graus de cidadania e, por outro lado, em dimensões da cidadania, pessoal, política, social. 
Haveria múltiplos de cidadania, nos planos nacional, regional e internacional (HÖFFE, 2003), na medida em que a comunidade internacional reconhece um estatuto do cidadão, identificado com o estatuto jusfundamental da pessoa, com direitos e deveres fundamentais e, noutro vértice, situações de subcidadania, como a de estrangeiros, refugiados, apátridas ou mesmo daqueles com insuficiente capacidade de exercício da cidadania decorrente da exclusão social.

Nesse ponto, Nabais (2007) identifica na confluência entre as noções de solidariedade e cidadania uma nova dimensão. Após uma primeira etapa liberal, de cidadania passiva, orientada para a proteção do indivíduo e da família, tendo a comunidade política como algo externo, sobreveio um segundo momento democrático, de uma cidadania ativa e participativa da vida pública. Agora, como terceira etapa apresenta-se uma cidadania responsavelmente solidária, em que o cidadão assume um novo papel, tomando consciência de que o seu protagonismo ativo na vida pública não se esgota no controle dos poderes públicos, passando pela assunção de encargos, responsabilidades e deveres fundamentais.

Não se trata de uma solidariedade romântica, de um voluntarismo, mas de deveres juridicamente impostos pelo ordenamento jurídico, sobretudo através da via da promoção ou do incentivo, da função promocional do Direito. Pode-se afirmar, na linha de Comparato (2006), que a solidariedade é o fecho da abóbada do sistema de princípios éticos, pois complementa, aperfeiçoa e compatibiliza liberdade e igualdade, pois enquanto a liberdade e a igualdade põem as pessoas umas diante das outras, a solidariedade as reúne, todas, no seio de uma mesma comunidade.

A esse respeito, Duvignaud (1986) alerta para o risco de uma banalização da ideia de solidariedade, para confortar a consciência de uns ou para conseguir esmola da má consciência de outros. Mas, assim como para a obra de Buffon (2009), esse estudo adota a concepção de solidariedade que, por um lado, está vinculada à solidariedade pelos direitos (paterna ou vertical) e, por outro, à solidariedade pelos deveres (fraterna ou horizontal). Quanto à solidariedade pelos direitos, passase à realização dos direitos sociais e de solidariedade, como os relacionados ao meio ambiente, à democracia, ao patrimônio cultural e, no que se refere à solidariedade pelos deveres, é cobrado dos cidadãos, da comunidade social ou da sociedade civil o cumprimento dos deveres perante outros indivíduos ou grupos sociais.

A concretização dos direitos fundamentais só é possível a partir do comprometimento de todos os cidadãos, tanto por meio de condutas negativas, um não fazer diante da fruição de direitos alheios, como um agir indispensável à vida em grupo, o que implica participação ativa dos cidadãos na vida pública e um empenho solidário na transformação das estruturas sociais. Portanto, reclama um mínimo de responsabilidade social no exercício das liberdades individuais e a existência de deveres jurídicos de respeito aos valores constitucionais e direitos fundamentais em dimensão objetiva e na esfera das relações privadas (SARLET, 2018). Desse modo, o necessário resgate dos deveres fundamentais contribui para a superação do discurso quantitativo e simbólico dos direitos fundamentais, valorizando o suporte material para sua aplicação e exercício, bem como aprimora 
a noção de cidadania sob a dimensão da responsabilidade social, como forma de equilibrar, com direitos e deveres, o estatuto jusfundamental da pessoa humana.

\section{Considerações finais}

A investigação das razões jurídicas e políticas da atrofia no desenvolvimento teórico dos deveres fundamentais conduz a caminhos que se cruzam e se conectam. A superação do primeiro momento do constitucionalismo e o atual contexto de universalização dos direitos fundamentais e da democracia exigem uma visão diferenciada. Exsurge a dimensão da solidariedade para completar a relação conflituosa entre liberdade e igualdade, bem como entre direitos e deveres das pessoas.

A sociedade se defronta com a proliferação de direitos, em sucessivas camadas de gerações ou dimensões, mas sente um enorme déficit de efetividade, assim como as crises econômicas mundiais expõem os custos dos direitos, de maneira a tornar insustentável a reivindicação de direitos fundamentais sob o viés exclusivo do direito subjetivo individual. Evidencia-se, com isso, que o ser humano, para viver com certa parcela de liberdade e igualdade em sociedade, deve estar dotado de um conjunto de direitos e deveres para com a coletividade, que não se sustenta sozinha, mas exige uma dimensão de solidariedade, cuja valorização dos deveres fundamentais converge, desde o pagamento de impostos para manutenção das estruturas e instituições garantidoras de direitos, até noções mais amplas como os deveres de voto em ordens democráticas e a preservação ambiental às futuras gerações.

Não é demais frisar que o Estado de bem-estar social é um modelo estatal caro, não apenas em razão do custo dos direitos, em especial os sociais (não há dúvida do necessário aprofundamento do debate sobre quem paga a conta dos direitos), mas, também, caro no sentido do apreço, de ser um modelo superior aos demais experimentados, no qual é possível fruir concomitantemente liberdade, igualdade e fraternidade. No sentido aqui defendido, a manutenção e a afirmação de uma sociedade livre e igualitária pressupõe sua imersão na dimensão da solidariedade, uma mudança de paradigma que leve em conta a complexidade social e a responsabilidade dos agentes públicos e privados no enfrentamento dos atuais e novos desafios.

Urge, assim, que se realize um esforço para o resgate teórico dos deveres fundamentais como categoria jurídica autônoma, apostando no seu desenvolvimento para qualificar o estatuto jusfundamental da pessoa humana, no qual haja um equilíbrio entre direitos e deveres fundamentais. Cuida-se de um empenho imprescindível para evitar que se confunda democracia com demagogia, impedindo-se um mergulho na era da irresponsabilidade, com riscos para os direitos fundamentais e para a perenidade do Estado constitucional.

O resgate do tema deveres fundamentais não se esgota em si mesmo, como mera incursão em um assunto pouco explorado, mas sua valorização é carregada de significado para o constitucionalismo contemporâneo, sob a dimensão mais recente dos direitos de solidariedade, confluindo para a eficácia 
na tutela dos direitos, no exercício da liberdade com responsabilidade e na construção de uma noção mais completa de cidadania.

\section{Referências}

BANDIERI, Luís María. Derechos fundamentales ìy deberes fundamentales? In: LEITE, George Salomão; SARLET, Ingo Wolfgang; CARBONELL, Miguel (org.). Direitos, deveres e garantias fundamentais. Salvador: JusPodivm, 2011. p. 211-244.

BARROSO, Luis Roberto. Curso de Direitos Constitucional contemporâneo. 5. ed. São Paulo: Saraiva, 2015.

BENTO XVI, Papa. Carta Encíclica Caritas in Veritate. Vaticano: Libreria Editrice Vaticana. 2009. Disponível em: http://w2.vatican.va/content/benedict-xvi/pt/encyclicals/ documents/hf_ben-xvi_enc_20090629_caritas-in-veritate.html. Acesso em: 21 out. 2017.

BRASIL. Constituição. República Federativa do Brasil de 1988. Brasília, DF: Senado Federal, 1988. Disponível em: http://www.planalto.gov.br/ccivil_03/constituicao/constituicaocompilado. htm. Acesso em: 16 jun. 2017.

BUFFON, Marciano. Tributação e dignidade humana: entre os direitos e deveres fundamentais. Porto Alegre: Livraria do Advogado, 2009.

CANOTILHO, José Joaquim Gomes. Direito constitucional e teoria da constituição. 7. ed. Coimbra, Portugal: Almedina, 2006.

CANOTILHO, José Joaquim Gomes; MORATO LEITE, José Rubens (org.). Direito constitucional ambiental brasileiro. São Paulo: Saraiva, 2007.

CARBONE, Carmelo. I doveri pubblici individuali nella Constituzione. Dott. A. Giuffré Editore: Milano, 1968.

CASTANHEIRA NEVES, António. Pessoa, direito e responsabilidade. Revista Portuguesa de Ciência Criminal, Lisboa, ano 6, n. 1, p. 9-43, jan./mar. 1996.

CHULVI, Cristina Pauner. El deber constitucional de contribuir al sostenimiento de los gastos públicos. Madrid: Centro de Estudios Políticos e constitucionales, 2001.

COMPARATO, Fábio Konder. Ética: direito, moral e religião no mundo moderno. São Paulo: Companhia das Letras, 2006.

DUVIGNAUD, Jean. A solidariedade: laços e sangue, laços de razão. Tradução: Casco Casimiro. Lisboa, Portugal: Instituto Piaget, 1986.

ESPOSITO, Roberto. Communitas: origen y destino de la comunidad. Traducción: Carlo Rodolfo Molinari Marotto. Buenos Aires: Amorrortu, 2012.

FERREIRA FILHO, Manuel Gonçalves. Curso de direito constitucional. 39. ed. São Paulo: Saraiva, 2013. 
GUASTINI, Riccardo. A constitucionalização do ordenamento jurídico: o caso italiano. In: CARBONELL, Miguel. Neoconstitucionalismo(s). Madrid: Editorial Trotta, 2003.

HÖFFE, Otfried. Visão República mundial: democracia na era da globalização. In: OLIVEIRA, Nythamar Fernandes de; SOUZA, Draiton Gonzaga de (org.). Justiça e direito. Porto Alegre: EdiPUCRS, 2003.

HOLMES, Stephen; SUNSTEIN, Cass. The cost of rights. Cambridge: Harvard University Press, 1999.

LANCHESTER, Fulco. Los deberes constitucionales en el derecho comparado. Tradução: Valentina Faggiani. ReDC, año 7, n. 13, p. 67-81, enero/junio/2010.

MARSHALL, Thomas Humphrey. Citizenship and social class. London: Pluto Press, 1992.

NABAIS, José Casalta. O dever fundamental de pagar impostos: contributo para a compreensão constitucional do estado fiscal contemporâneo. Coimbra, Portugal: Almedina, 2015.

NABAIS, José Casalta. Por uma liberdade com responsabilidade: estudos sobre direitos e deveres fundamentais. Coimbra, Portugal: Coimbra Editora, 2007.

ORGANIZAÇÃO DAS NAÇÕES UNIDAS. Declaração Universal dos Direitos Humanos. 1948. Disponível em: http://www.onu.org.br/img/2014/09/DUDH.pdf. Acesso em: 2 jul. 2017.

ORGANIZAÇÃO DOS ESTADOS AMERICANOS. Declaração americana dos direitos e deveres do homem. 1948. Disponível em: http://www.oas.org/pt/cidh/ mandato/Basicos/declaracion.asp. Acesso em: 2 jul. 2017.

PECES-BARBA MARTÍNEZ, Gregorio. Los deberes fundamentales. Doxa, Alicante, n. 4. p. 329-341, 1987.

PÉREZ LUÑO, Antonio Enrique. Los derechos fundamentales. 11. ed. Madrid: Tecnos, 2013.

SARLET, Ingo Wolfgang. A eficácia dos direitos fundamentais. 9. ed. Porto Alegre: Livraria do Advogado, 2018.

SCHMITT, Carl. Teoría de la Constitución. Madrid: Alianza Editorial, 1986.

SILVA, Matheus Passos. A cidadania ativa como mecanismo para o cumprimento do dever fundamental de preservação do meio ambiente por parte do cidadão. In: SILVA, Matheus Passos et al. (org.). Primeiro compêndio científico do NELB. Brasília, DF: Velstnik, 2015. v. 1, p. 204-227.

SIQUEIRA, Julio Pinheiro Faro Homem de. Deveres como condição para a concretização de direitos. Revista de direito constitucional e internacional, ano 20, v. 79, p. 167-209, abr./jun. 2012.

SIQUEIRA, Julio Pinheiro Faro Homem de. Elementos para uma teoria dos deveres fundamentais: uma perspectiva jurídica. Revista de direito constitucional e internacional, São Paulo: RT, ano 24, v. 95, abr./jun. 2016.

VIOLANTE, Luciano. Il doveri di avere doveri. Torino: Giulio Einaudi, 2014. 